\title{
Newborn Care Practice and Associated Factors among Mothers who gave Birth within One Year in Mandura District, Northwest Ethiopia
}

Tewodros Tegene ${ }^{1}$, Gashaw Andargie ${ }^{2}$, Ansha Nega $^{3}$ and Kedir Yimam ${ }^{4^{*}}$

${ }^{1}$ Department of Nursing, Pawe Health Science College, PO Box: 50, Pawe, Ethiopia

${ }^{2}$ Department of Reproductive Health, Institute of Public Health, College of Medicine and Health Science, University of Gondar, PO Box:196, Gondar, Ethiopia

${ }^{3}$ Department of Health Promotion and Communication, Institute of Public Health, College of Medicine and Health Science, University of Gondar, PO Box:196, Gondar, Ethiopia

${ }^{4}$ Department of Public Health, College of Medicine and Health Science, Debre Markos University, PO Box:269, Debre Markos, Ethiopia

"Corresponding author: Kedir Yimam, Department of Public Health, College of Medicine and Health Science, Debre Markos University, PO Box:269, Debre Markos, Ethiopia, Tel: +251-910-889265; E-mail:kedirymam331@gmail.com

Rec date: November 17, 2014, Acc date: February 22, 2015, Pub date: February 28, 2015

Copyright: () 2015 Yimam K, et al. This is an open-access article distributed under the terms of the Creative Commons Attribution License, which permits unrestricted use, distribution, and reproduction in any medium, provided the original author and source are credited.

\begin{abstract}
Introduction: Neonatal deaths in general, early neonatal deaths in particular now represent two-third of infant deaths and one-third of under-five deaths worldwide. Ethiopia has the sixth highest number of newborn death. Many newborn deaths can be averted through changes in household level practices regarding delivery and newborn care. However, in Ethiopia scientific evidences on level of newborn care practice are scanty and inconclusive. Therefore, this study aimed at assessing newborn care practice and factors associated with them.
\end{abstract}

Methods: Community based cross sectional study was undertaken in Mandura district from August to September 2013. Stratified multi-stages sampling technique was employed to select 539 study participants. Structured and pretested questionnaire was used for data collection via face to face interview. Descriptive statistics were used for summarization and presentation of the data. Binary logistic regressions were used to identify factors associated with newborn practice of mothers.

Results: Among mothers who gave births within one year, $216(40.6 \%)$ with $95 \% \mathrm{Cl}(36.5-44.5 \%)$ of them had good newborn care practice. The likelihood of good newborn practice was higher among urban residents (AOR=3.26 $95 \% \mathrm{Cl}: 1.90-5.57)$ and among those who attend primary school (AOR=2.29 95\% Cl: $1.05-5.0)$ and high school and above (AOR=2.68 95\% Cl: (1.20-6.0) level. Having at least one ANC follow up (AOR=1.89 95\% Cl: 1.18-3.03), preparedness for delivery ( $A O R=1.9295 \% \mathrm{Cl}: 1.01-3.64)$, knowing first breast feeding time (AOR=1.74 95\% Cl: $1.12-2.71)$ and knowing first bathing time $(A O R=3.7995 \% \mathrm{Cl}: 2.51,5.75)$ were significantly associated with good newborn care practice of mothers.

Conclusion: This study showed that the level of newborn care practice of more than half of mothers is poor. Residence, educational status of mothers, knowledge of mothers on initiation of breast feeding and time of first bathing, ANC follow up and preparedness for delivery independent predictors for good newborn practice. Therefore, interventions targeted on the independent predictors can improve newborn care practice of mothers.

Keywords: Newborn care practice; Ethiopia

\section{Introduction}

Global under five and infant mortality rates have declined over the past four decades, but high neonatal mortality rates have remained relatively unchanged. It is estimated that 7.7 million children under five years die in a year, out of which about 3.1 million babies die in the first four weeks of life and $99 \%$ of these deaths occur in low income countries [1-4]. Although neonatal mortality rates are also decreasing globally, Africa is experiencing much slower declines than other regions [2]. Each year, at least 1.16 million African babies die in the first 28 days of life and 850,000 of these babies do not live past the week they are born. A vast majority of these deaths are occurring in Sub-Saharan Africa countries and has also shown the slowest progress in reducing newborn deaths, especially deaths in the first week of life [5].
Millennium Development Goal-4 for child survival cannot be met without significant reductions in neonatal mortality [6]. The World Health Organization recommends improving newborn care practices at birth in order to reduce morbidity and mortality. These have been described as Essential Newborn Care (ENC) practices [7-9]. The world health organization guideline defined essential newborn care to encompass cleanliness, thermal protection, and initiation of breathing, initiation of breast feeding, eye care, immunization, management of illness, and the care of low birth weight infants. For a mother and her family, this means preparing for birth, choosing a safe place for delivery, keeping the process clean, avoiding the cold, initiation and exclusively breast feeding, and understanding and reacting to potential neonatal problems [10]. Therefore, essential newborn care is very important in preventing neonatal deaths, particularly essential care of the normal newborn to prevent illness, extra care of low birth weight babies, and access to quality emergency care for the sick newborn [11].

In Ethiopia neonatal morbidity and mortality rates are among the highest in the world. Around 122,000 newborns die every year and the 
neonatal mortality rate is 37 per 1000 live births [12,13]. Since nearly $90 \%$ of births and majority of deaths take place at home, away from the reach of skilled providers, many newborn deaths can be averted through changes in household level practices regarding delivery and newborn care $[6,12]$. To change the practice at the household level, new innovative strategies must be developed for safe home deliveries including essential neonatal care, besides devising means of proper care of the neonate in domestic settings and ensuring proper referral of those neonates who cannot be managed at home [1]. In Mandura district there is also a common practice called forest delivery, when their delivery time starts to approach delivery mother will be separated from family and moves to nearest forest to deliver there. In order to design and prioritize interventions at the country level that reduce neonatal morbidity and mortality understanding newborn care practices of such type of community is necessary. Therefore, this study aimed at assessing newborn care practice and associated factors among mothers who gave birth within one year in Mandura district.

\section{Methods}

\section{Study design and study settings}

Community based cross sectional study was used in Mandura district from august to September 2013. The Mandura district is located $553 \mathrm{~km}$ from the capital city Addis Ababa in the Metekel zone of the Benishangul Gumuz region. The district is divided in to 20 administrative units (kebeles), 3 urban and 17 rural, and has an estimated population size of 47,562.

\section{Source and study population}

The source populations were all reproductive age women who gave births within one year in Mandura district. Those who were selected by two stage sampling technique and permanent residents were included in the study. Mothers who gave still birth and who were seriously ill during the interview were excluded.

\section{Sampling}

The sample size for this study was determined using single population proportion formula considering prevalence of good newborn care practice of $20 \%(\mathrm{P}=0.2)$ at $95 \%$ confidence interval and $5 \%$ margin of error. Adding non-response rate of $10 \%$ and considering the design effect of two a total of 539 mothers were the final sample size of this study. Stratified multi-stage sampling technique was employed to select the required sample size. At stage one, from 17 rural kebeles six and from three urban kebeles two were selected using lottery method. At stage two, computer generated simple random sampling technique was employed after conducting census to determine eligible mothers of sampled Kebeles. The sample sizes were distributed to each kebeles proportional to the eligible mothers of the kebeles.

\section{Variables}

Dependent variable: newborn care practice.

Independent variables: socio-demographic factors (age, ethnicity, residence, educational status, occupation, marital status, average monthly income and family size), knowledge of mothers regarding newborn practice, utilization of maternal health care (ANC, place of delivery, birth plan, skilled birth attendance).

\section{Data collection}

Data was collected using structured interviewer administered questionnaire. It was prepared in English, translated to Amharic and then translated back to English to check the consistency. The questionnaire was pre-tested on 30 individuals from part of the district which was not included in the study. Three Bsc nurse supervisors and 14 health extension workers as data collector were employed and trained for one day on the questionnaire and the processes of data collection and submission on due time. Interviewers were supervised at each site, regular daily review meetings were held between the data collectors and the principal investigator. Two additional visits were made if a respondent was not found in the first visit. The collected data were reviewed and checked for consistency and completeness before data entry.

\section{Operational definitions}

Initiation of breastfeeding: the recommended practice of breastfeeding a newborn baby within one hour after birth.

Baby bathing: the practice of newborn baby bathing only after 24 hours of birth.

Cord Cutting: the practice of cutting a cord with a new blade or a boiled blade.

Thermal care: when the new born was dried and wrapped after birth. In this study, new born care practice is dichotomized based on the four newborn care practices mentioned above. Those mothers who reported at least three of mentioned practices were categorized as "good newborn care practice" otherwise they categorized as "poor newborn care practice".

\section{Data processing and analysis}

Data was checked, coded and entered to Epi-info version 3.3.2 and was exported to SPSS version 20 for analysis. Univariate, bivariate and multivariate analyses were considered. All variables were inserted in to the multiple logistic regression model and backward stepwise likelihood ratio was used to identify independent predictors. Statistically significant association between the outcome variable and independent variables was declared at p-value less than 0.05 .

\section{Ethical consideration}

Ethical clearance was obtained from ethical review board of university of Gondar. Permission was also obtained from Mandura district health office to conduct the study. Each study participant was adequately communicated the necessary information about the study and the right to withdraw at any time during the interview. Finally, informed consent was obtained prior to data collection.

\section{Results}

\section{Socio-demographic characteristics}

A total of 532 women responded to the questionnaire, yielding a response rate of $98.7 \%$. Among study subjects 418 (78.6\%) were rural in residents. The mean ( \pm SD) age of respondents was 30.8 ( \pm 5.23 ) years. More than half, $308(57.9 \%)$ of them were in $25-34$ years age group. Majority, $517(97.2 \%)$ of them were married. About 318 $(59.8 \%)$ and $240(45.1 \%)$ of them were gumuz in ethnicity and 
Citation: Tegene T, Andargie G, Nega A, Yimam K (2015) Newborn Care Practice and Associated Factors among Mothers who gave Birth within One Year in Mandura District, Northwest Ethiopia. Clinics Mother Child Health 12: 172. doi:10.4172/2090-7214.1000172

Page 3 of 7

orthodox in religion respectively. Four hundred eighty six $(91.4 \%)$ were house wives. Majority, 438 (82.3\%) of them were illiterate. Two hundred eighty (52.6\%) of them were living with 3-5 family members (Table 1).

\section{Preparedness for delivery and delivery assistance}

Out of the total study participants 324 (60.9\%) of them delivered at home. Regarding delivery assistance $162(30.5 \%)$ of them assisted by family and/or friends. Of those who had history of ANC visit, 117 $(42.9 \%)$ of them reported less than two visit. Four hundred twenty two (79.3\%) women reported that they prepared necessary materials for delivery. Among study participant, 417 (78.4\%) of them had plan where they would like to deliver their babies. Among these more than half, $220(52.3 \%)$ of them said that they planned to deliver at home (Table 2).

\section{Knowledge of respondents regarding newborn care}

Among respondents, 375(70.5\%) of them heard at least one immediate new born care practice method. Among these more than half, 203 (54.1\%) of mothers were first heard from health workers. Off those who knew newborn care practice methods, 138 (36.8\%), 297 (79.2\%), 198 (52.8\%), 233 (62.1\%), 203 (54.1\%) and 228 (60.8\%) of mothers knew immediate placement of the baby on mothers abdomen, safe cord cutting, drying and wrapping the baby before delivery of placenta, breast feeding of the baby within one hour of delivery, importance of colostrum and bathing of the baby after 24 hours respectively (Table 3 ).

\begin{tabular}{|c|c|c|}
\hline Variable & Frequency & Percentage (\%) \\
\hline \multicolumn{3}{|l|}{ Age } \\
\hline $15-24$ & 80 & 15 \\
\hline $25-34$ & 308 & 57.9 \\
\hline $35-44$ & 144 & 27.1 \\
\hline \multicolumn{3}{|l|}{ Ethnicity } \\
\hline Gumuz & 318 & 59.8 \\
\hline Agew & 127 & 23.9 \\
\hline Amhara & 63 & 11.8 \\
\hline Shinasha/Oromo & 24 & 4.5 \\
\hline \multicolumn{3}{|l|}{ Residence } \\
\hline Urban & 114 & 21.4 \\
\hline Rural & 418 & 78.6 \\
\hline \multicolumn{3}{|l|}{ Marital status } \\
\hline Married & 517 & 97.2 \\
\hline single & 9 & 1.7 \\
\hline widowed/divorced & 6 & 1.1 \\
\hline \multicolumn{3}{|l|}{ Religion } \\
\hline Orthodox & 240 & 45.1 \\
\hline Traditional & 156 & 29.3 \\
\hline
\end{tabular}

\begin{tabular}{|c|c|c|}
\hline Protestant/catholic & 92 & 17.3 \\
\hline Muslim & 44 & 8.3 \\
\hline \multicolumn{3}{|l|}{ Educational status } \\
\hline No formal education & 438 & 82.3 \\
\hline Primarily education & 43 & 8.1 \\
\hline $\begin{array}{l}\text { Secondary education } \\
\text { and above }\end{array}$ & 51 & 9.6 \\
\hline \multicolumn{3}{|l|}{ Monthly income } \\
\hline$<300$ birr & 23 & 4.3 \\
\hline 301-600 birr & 225 & 42.3 \\
\hline 601-1000 birr & 218 & 41 \\
\hline >1001 birr & 66 & 12.4 \\
\hline \multicolumn{3}{|l|}{ Employment status } \\
\hline House wife/farmer & 486 & 91.4 \\
\hline merchant & 12 & 2.3 \\
\hline government employer & 22 & 4.1 \\
\hline others & 12 & 2.3 \\
\hline \multicolumn{3}{|l|}{ Family size } \\
\hline 2-Jan & 16 & 3 \\
\hline 5-Mar & 280 & 52.6 \\
\hline 6 and above & 236 & 44.4 \\
\hline
\end{tabular}

Table 1: Socio demographic characteristics of mothers in Mandura district, Northwest Ethiopia, $2013(\mathrm{n}=532)$.

\begin{tabular}{|l|l|l|}
\hline Variable & Frequency & Percentage (\%) \\
\hline ANC visit & 273 & 51.3 \\
\hline Yes & 259 & 48.7 \\
\hline No & 117 & 42.9 \\
\hline Number of ANC visit (n=273) & 26.7 \\
\hline$\leq$ two visit & 73 & 22 \\
\hline Three visit & 60 & 8.5 \\
\hline$\geq$ four visit & 23 & \multicolumn{2}{l}{} \\
\hline don't remember & 422 & 79.3 \\
\hline Preparedness for delivery & 20.7 \\
\hline Yes & 110 & 70.68 \\
\hline No & 376 & 57 \\
\hline Materials prepared for delivery (n=422) & \\
\hline Food & 307 & \\
\hline Cloth &
\end{tabular}


Citation: Tegene T, Andargie G, Nega A, Yimam K (2015) Newborn Care Practice and Associated Factors among Mothers who gave Birth within One Year in Mandura District, Northwest Ethiopia. Clinics Mother Child Health 12: 172. doi:10.4172/2090-7214.1000172

Page 4 of 7

\begin{tabular}{|c|c|c|}
\hline Finance & 210 & 39.48 \\
\hline Transport & 137 & 25.7 \\
\hline \multicolumn{3}{|l|}{ Delivery place plan } \\
\hline Yes & 417 & 78.4 \\
\hline No & 115 & 21.6 \\
\hline \multicolumn{3}{|c|}{ Place of delivery plan $(n=417)$} \\
\hline Home & 220 & 52.3 \\
\hline Institution & 185 & 44 \\
\hline Other & 16 & 3.8 \\
\hline \multicolumn{3}{|l|}{ Place of delivery } \\
\hline Home delivery & 324 & 60.9 \\
\hline Institutional delivery & 124 & 23.3 \\
\hline Forest delivery* & 84 & 15.8 \\
\hline \multicolumn{3}{|l|}{ Delivery attendant } \\
\hline Family/friend & 162 & 30.5 \\
\hline Skill provider & 159 & 29.9 \\
\hline Self-delivery & 145 & 27.3 \\
\hline TBA & 66 & 12.4 \\
\hline \multicolumn{3}{|l|}{ Use of delivery kit } \\
\hline Yes & 185 & 34.8 \\
\hline No & 347 & 65.2 \\
\hline
\end{tabular}

Table 2: Preparedness for delivery and delivery assistance of mothers in Mandura district, Northwest Ethiopia, 2013. ${ }^{\star}$ forest delivery is practice in the study area when their delivery time starts to approach delivery mother will be separated from family and moves to near forest.

\begin{tabular}{|l|l|l|}
\hline Knowledge variables & Frequency & Percentage (\%) \\
\hline Heard about immediate newborn care \\
\hline \multicolumn{2}{|l|}{} \\
\hline Yes & 375 & 70.5 \\
\hline No & 157 & 29.5 \\
\hline Source of information & \multicolumn{2}{|l|}{} \\
\hline Health worker & 203 & 54.1 \\
\hline Family/friend & 114 & 30.4 \\
\hline Neighbors & 47 & 12.5 \\
\hline Media & 13 & 9.06 \\
\hline Placement of the baby on mother's abdomen before delivery of placenta \\
\hline Yes & 138 & 36.8 \\
\hline No & 237 & 63.2 \\
\hline
\end{tabular}

\begin{tabular}{|c|c|c|}
\hline \multicolumn{3}{|c|}{ Safe cord cutting } \\
\hline Yes & 297 & 79.2 \\
\hline No & 78 & 20.8 \\
\hline \multicolumn{3}{|c|}{ Drying and wrapping the baby before delivery of the placent } \\
\hline Yes & 198 & 52.8 \\
\hline No & 177 & 47.2 \\
\hline \multicolumn{3}{|c|}{ Breast feeding of the baby within one hour of delivery } \\
\hline Yes & 233 & 62.1 \\
\hline No & 142 & 37.9 \\
\hline \multicolumn{3}{|c|}{ The importance of colostrum } \\
\hline Yes & 203 & 54.1 \\
\hline No & 172 & 45.9 \\
\hline \multicolumn{3}{|c|}{ Bathing of the baby after 24 hours ( $n=375$ ) } \\
\hline Yes & 228 & 60.8 \\
\hline No & 147 & 39.2 \\
\hline \multicolumn{3}{|c|}{ Know at least one neonatal problem ( $n=375$ ) } \\
\hline Yes & 422 & 79.3 \\
\hline No & 110 & 21.2 \\
\hline
\end{tabular}

Table 3: Knowledge of mothers regarding immediate newborn care practice in Mandura district, Northwest Ethiopia, $2013(\mathrm{n}=532)$.

\section{Newborn care practice of mothers}

Nearly one third $(74.4 \%)$ of mothers reported that their babies were delivered on their abdomen after birth. Three hundred six (57.5\%) of mothers reported the practice of drying and wrapping the baby before delivery of the placenta. Among respondents, 318 (59.8\%) of them reported the cord cutting with new or boiled razor blade. Regarding breast feeding, 256 (48.1\%) of mothers began breast feeding within first hour of birth. About 201 (37.8\%) of mothers bathed their baby after 24 hours of birth (Table 4).

\begin{tabular}{|l|l|l|}
\hline Variables & Frequency & Percentage (\%) \\
\hline \multicolumn{2}{|l|}{ Placement of the baby after delivery } \\
\hline On the mother's abdomen & 401 & 74.4 \\
\hline Near the delivery surface & 104 & 19.3 \\
\hline On another bed separately & 26 & 4.8 \\
\hline Transferred to father/relatives & 6 & 1.1 \\
\hline don't remember & 2 & 0.4 \\
\hline Thermal care & 306 & 57.5 \\
\hline $\begin{array}{l}\text { Dried and wrapped immediately } \\
\text { dried and wrapped }\end{array}$ & 226 & 42.5 \\
\hline $\begin{array}{l}\text { Not } \\
\text { immediately }\end{array}$ & \\
\hline
\end{tabular}




\begin{tabular}{|l|l|l|}
\hline \multicolumn{2}{|l|}{ Cord cutting } \\
\hline New or boiled razor blade & 318 & 59.8 \\
\hline Used razor blade & 214 & 40.2 \\
\hline Material on the umbilical cord & 121 & 22.7 \\
\hline Yes & 411 & 77.3 \\
\hline No &
\end{tabular}

Applied material on the cord $(n=121)$

\begin{tabular}{|l|l|l|}
\hline Ash & 86 & 71.07 \\
\hline Butter & 22 & 18.18 \\
\hline Cow dung & 13 & 10.74 \\
\hline
\end{tabular}

Initiation of breast feeding

\begin{tabular}{|c|c|c|}
\hline Within 1 hour & 256 & 48.1 \\
\hline After 1 hour & 276 & 51.9 \\
\hline \multicolumn{3}{|c|}{ Frequency of breast feeding } \\
\hline$\geq 8$ times & 237 & 44.5 \\
\hline$<8$ times & 295 & 55.5 \\
\hline
\end{tabular}

\section{Time of first bathing}

\begin{tabular}{|l|l|l|}
\hline After 24 hours & 201 & 37.8 \\
\hline Within 24 hour & 331 & 62.2 \\
\hline
\end{tabular}

\section{Additional diet}

\begin{tabular}{|l|l|l|}
\hline Yes & 159 & 29.7 \\
\hline No & 373 & 70.1 \\
\hline Immunization & 236 & 44.4 \\
\hline Yes & 296 & 55.6 \\
\hline No & & \\
\hline
\end{tabular}

\section{Exposing the baby to sunlight}

\begin{tabular}{|l|l|l|}
\hline Yes & 457 & 85.9 \\
\hline No & 75 & 14.1 \\
\hline
\end{tabular}

Table 4: Newborn care practice of mothers in Mandura district, Northwest Ethiopia, 2013 ( $\mathrm{n}=532)$.

Taking the four major newborn care practices of mothers (breast feeding initiation, bathing time, cord cutting and thermal care of the baby), $216(40.6 \%)$ of them practiced three of them which indicates good newborn care practice (Figure 1).

\section{Factors associated with newborn care practice}

In multivariate analysis; residence, educational status, history of ANC visit, delivery preparedness, knowing first baby bathing time and knowing first breast feeding time were found statistically significant associated with newborn care practice of respondents.

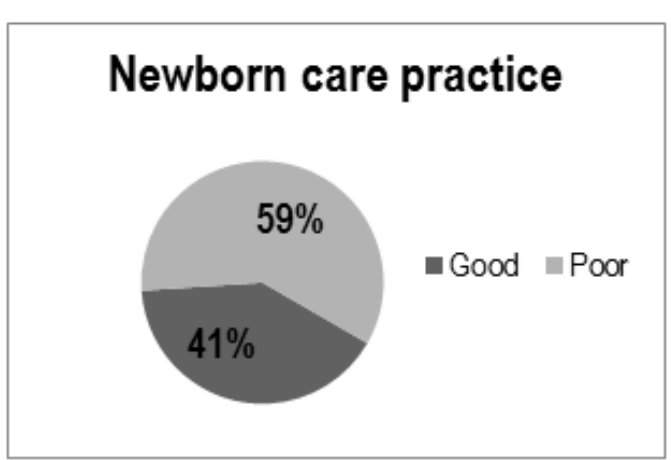

Figure 1: Newborn care practice of mothers in Mandura district, Northwest Ethiopia, 2013.

The likelihood of good newborn practice was higher $(\mathrm{AOR}=3.26$ 95\% CI: 1.90, 5.57) among urban residents. Those who were at primary school $(\mathrm{AOR}=2.2995 \% \mathrm{CI}: 1.05,5.0)$ and high school and above level (AOR=2.68 95\% CI: 1.20, 6.0) were significantly associated with good newborn care practice as compared to those who have no formal education. Having at least one ANC visit (AOR=1.89 95\% CI: $1.18,3.03)$ and preparedness for delivery (AOR $=1.9295 \% \mathrm{CI}: 1.01$, 3.64) were positively associated with good newborn care practice of mothers. The odds of good newborn care practice among mothers who know first breast feeding time (AOR=1.74 95\% CI: 1.12, 2.71) and first bathing time (AOR=3.79 95\% CI: 2.51, 5.75) were higher as compared to their counterparts (Table 5).

\section{Discussion}

Among mothers, $48.1 \%$ of them initiated breast feeding within one hour of birth. One study conducted in four regions of Ethiopia (Amhara, Oromia, Tigrai and Southern Nations Nationalities and Peoples Region (SNNPR)) found that $52.1 \%$ of newborns were breastfed within the first hour after delivery [14]. The same finding was reported by EDHS 2011 which was 52\% [6]. Community based study conducted in Jimma also reported that $50 \%$ of infants received breast milk within one hour of delivery [15]. The slight difference in breast feeding initiation of this study with the above similar Ethiopian studies could be explained by larger proportion of respondents were from rural kebeles where timely initiation was less likely to be practiced. However, this was higher as compared to studies conducted in rural Nepal (7\%), Bangladesh (11.2\%), Ghana (41.6\%) and Tanzania (18\%) [16-19]. Ideally, newborn should not be bathed until at least 24 hours after delivery to maintain body temperature and minimize the risk of hypothermia [10]. In this study $37.8 \%$ infant were bathed after 24 hours of birth. One study in Jimma reported that about $58.4 \%$ of mothers bathed their babies after 24 hours of birth which is higher compared to the present finding [15]. The socio-economic status of Mandura district which is found in Benishangul Gumz region expected to be lower than Jimma town which is located in Oromia region could be the possible explanation. However, this finding was higher as compared to study conducted in four regions of Ethiopia which was $25.3 \%$ [14]. The same studies conducted in rural Nepal and Ghana reported that $16.6 \%$ and $1.2 \%$ of mothers respectively bathed their baby after 24 hours of delivery which is much lower than the present finding $[16,19]$. However, this finding was consistent with study done in rural Bangladesh which was 35\% [9]. 
In this study $57.5 \%$ of mothers dried and wrapped their baby immediately after delivery. The same study conducted in four regions of Ethiopia showed that $63.2 \%$ of babies dried and wrapped before delivery of the placenta [14]. The difference with the above finding could be due to socio-demographic status of the four regions expected to be higher than Benishangul Gumuz region. However, this finding was higher as compared to studies done in Tanzania (27\%), Bangladesh (21\%) and Ghana (20\%) [17-19]. In this study, 59.8\% of mothers reported that cutting of the cord with new or boiled razor blade. This finding found to be lower than the same studies conducted in four regions of Ethiopia (Amhara, Oromia, Tigrai and Southern Nations Nationalities and Peoples Region (SNNPR)) which was 63.5\% [14]. The socio-economic status of the study region expected to be lower than these regions which might be the possible explanation for the difference. This finding was much lower than other abroad studies done in urban areas of Western Nepal (90.4\%), rural areas of Nepal (70.7\%), Northern Ghana (90.9\%), and Southern Tanzania (95\%) $[16,18,19,20]$. The difference with the above findings could be due to the reason that in the current study majority of respondents gave birth at home or forest. However, this finding was found to be in congruent with study done in Eastern Uganda (57\%) [9]. in this study the overall good newborn practice of mothers was found to be $40.6 \%$.

Those mothers who were living in urban area were three times more likely to have good new born care practice than those who were living in rural area. The possible explanation for this could be due to good access and utilization of health service in urban than rural area and mothers in rural areas expected to have lower educational status than mothers in urban areas. Attending primarily school and above level were positively associated with good new born practice of mothers. A study in Jimma showed that women who were at high school and above level were 2.68 times more likely to have good new born care practice than who had no formal education [15]. Moreover, one study in Nepal showed that women who had higher level of education were significantly and positively associated with the practice of safe cord cutting and bathing baby after 24 hours of birth [16]. This could be explained by the level of understanding towards the importance of ANC utilization is expected to be high in educated mothers.

In current study women who had history of at least one ANC visit were more likely to have good newborn practice as compared to their counter parts. This finding was consistent with a study done in Uganda, Tanzania, Nepal and Jimma $[9,15,16,18]$. This might be due to women who attended ANC have the possibility of getting information about the components and the importance of newborn care practice from health care providers.

Those mothers who knew first bathing and first breast feeding time of their baby were more likely to have good newborn practice than their counter parts. This was in line with study conducted in urban areas of Western Nepal [20]. The possible explanation for this could be having knowledge about bathing time and breastfeeding time makes them to practice it. Preparedness for delivery found to be significantly and positively associated with good newborn practice of mothers. This is in line with study conducted in Uganda [9].

Among the limitation of this study; first breast feeding time and first bathing time were subjected to recall bias. Difficulty of inferring casual association due to cross sectional nature of the study is also another limitation of this study. Despite the above limitations, use of community based study and inclusion of rural kebeles which increase the generalizability of the study is the strength of this study.

\section{Conclusion}

This study had showed that the level of good new born practice found to be low. Living in urban area, attending primary school and above, having knowledge about first breast feeding time and first bathing time, attending ANC and preparedness for are independent predictors for good newborn practice of mothers. In order to improve the newborn practice of mothers giving special attention for women education and increasing awareness of pregnant mothers is beneficial. There is a need of also improving antenatal care follow up level of pregnant mothers.

\section{Acknowledgement}

We would like to pass our gratitude to our friends who helps us in proposal and thesis writing for their valuable comments and encouragements. We would like to acknowledge also supervisors, data collectors and study participants for their timely submission and commitment. We would like to thank Gondar College of Medicine and Health Science for arranging internet and library services. Last but not least, thanks to Metekel Zonal Health Office, Mandura District Health Office and Pawi Health Science College for its support and collaboration throughout this project.

\section{References}

1. Sartaj A, Gagan A, Parul G, Vijay K, and Ashish P (2012) Assessment of the Newborn Care Practices in Home Deliveries among Urban Slums of Meerut, UP India. J Community Med Health Education 2: 1-4.

2. Mohammad HK, Fazal-ur-Rahman K, Nargis N, Ghazala H, Seema G, et al. (2006) Essential newborn care practice in hospital versus home deliveries. Gomal Journal of Medical Sciences 4: 7-9.

3. Rajaratnam JK, Marcus JR, Flaxman AD, Wang H, Levin-Rector A, et al. (2010) Neonatal, post neonatal, childhood, and under-5 mortality for 187 countries, 1970-2010: a systematic analysis of progress towards millennium development goal 4. Lancet 375: 1988-2008.

4. Oestergaard MZ, Inoue M, Yoshida S, Mahanani WR, Gore FM, et al. (2011) Neonatal mortality levels for 193 countries in 2009 with trends since 1990: a systematic analysis of progress, projections, and priorities. PLoS Med 8: e1001080.

5. The partnership for maternal, newborn and child health (2012) Opportunities for Africa's Newborns," Practical data, policy and programmatic support for newborn care in Africa: 250.

6. Charlotte W (2010) Care of the newborn: Community perceptions and health seeking behavior. Ethiop J Health Dev 24: 110-114.

7. Darmstardt GL, Bhatta ZA, Cousens S, Adam A, Walker N, et al. (2005) Evidence Based Cost Effective Interventions; How Many Newborns Can We Save? Lancet 365: 977-988.

8. Marsh DR, Darmstadt GL, Moore J, Daly P, Oot D, et al. (2002) Advancing Newborn Health and Survival in Developing Countries: A Conceptual Framework. J Perinatol 22: 572-576.

9. Waiswa P, Peterson S, Tomson G, Pariyo GW (2010) Poor Newborn Care Practices-A population Based Survey in Eastern Uganda. BMC Pregnancy and Childbirth 10: 9.

10. Technical working group on Essential Newborn care, World Health Organization (1996) Essential Newborn Care: A Report of a Technical Working Group, WHO, Geneva, Switzerland.

11. Gurung G (2008) Practices on immediate care of newborn in the communities of Kailali district. Nepal Med Coll J 10: 41-44.

12. Central Statistical Agency and ICF Macro (2011) Ethiopia Demographic and Health Survey, Calverton, Maryland, USA.

13. Lawn JE, Kinney MV, Black RE, Pitt C, Cousens S, et al. (2012) Newborn survival: a multi-country analysis of a decade of change. Health Policy Plan 27: iii6-iii28. 
Citation: Tegene T, Andargie G, Nega A, Yimam K (2015) Newborn Care Practice and Associated Factors among Mothers who gave Birth within One Year in Mandura District, Northwest Ethiopia. Clinics Mother Child Health 12: 172. doi:10.4172/2090-7214.1000172

Page 7 of 7

14. Callaghan-Koru JA, Seifu A, Tholandi M, Graft-Johnson JD, Daniel E, et al. (2013) Newborn care practices at home and in health facilities in 4 regions of Ethiopia. BMC Pediatrics 13: 198.

15. Girma T, Nida H (2008) Traditional newborn care in jimma town, Southwest Ethiopia. Ethiop J Health Sci 18: 79-86.

16. Tuladhar S (2010) The determinants of good newborn care practices in the rural areas of Nepal.

17. Shahjahan M, Ahmed MR, Rahman MM, Afroz A (2012) Factors affecting newborn care practices in Bangladesh. Paediatr Perinat Epidemiol 26: 13-18.
18. Penfold S, Hill Z, Mrisho M, Manzi F, Tanner M, et al. (2010) A Large Cross-Sectional Community Based Study of Newborn Care Practices in Southern Tanzania. PLoS ONE 5: e15593.

19. Saaka M, Iddrisu M (2014) Patterns and Determinants of Essential Newborn Care Practices in Rural Areas of Northern Ghana. International Journal of Population Research.

20. Chandrashekhar TS, Hari SJ, Binu VS, Sabitri G, Neena C (2006) Home delivery and newborn care practices among urban women in western Nepal: a questionnaire survey. BMC Pregnancy Childbirth 6: 27. 